\title{
Reduced pleural drainage, length of stay, and readmissions using a modified Fontan management protocol
}

\author{
Nancy A. Pike, PhD, ${ }^{a, b}$ Carol A. Okuhara, MN, ${ }^{a}$ Joy Toyama, MS, ${ }^{b}$ Barbara P. Gross, MSN, ${ }^{a}$ \\ Winfield J. Wells, MD, ${ }^{a, c}$ and Vaughn A. Starnes, MD ${ }^{a, c}$
}

\begin{abstract}
Background: Persistent pleural effusions after the Fontan procedure contribute to prolonged hospitalization and increased costs. We report our experience using a modified Wisconsin Fontan protocol to reduce chest tube drainage and hospital length of stay (LOS).

Methods: Single institutional retrospective chart review of 120 consecutive patients ( 60 before and 60 after initiation of our protocol) undergoing an extracardiac Fontan procedure from January 2004 to February 2007. Protocol influence was assessed by comparing group differences on duration of pleural drainage, requirement for nothing by mouth/total parenteral nutrition, hospital LOS, readmission for pleural effusion, and total hospital costs.
\end{abstract}

Results: Groups were similar in demographic characteristics, single ventricle morphology, preoperative hemodynamic parameters, and operative and immediate postoperative management. Median duration of pleural drainage and hospital LOS was reduced in the post- versus preprotocol groups: 4 days (interquartile range $[\mathrm{IQR}], 4-5$ days) pre versus 6 days (IQR, 5-10 days) $(P<.0001)$ and 6 days (IQR, 5-9 days) versus 8 days (IQR, 6-13 days) $(P=.005)$, respectively. Pleural drainage lasting $>1$ week was also less common postprotocol: 23 $(38 \%)$ before versus $7(12 \%)$ after $(P=.001)$. Fewer postprotocol patients required nothing by mouth/total parenteral nutrition to control effusions: 5 pre versus 0 post $(P=.06)$, and fewer readmissions for effusions ( 14 before vs 7 after $[P=.1])$. An average total cost savings of $22 \%$ and readmissions savings of $29 \%$ resulted in nearly $\$ 500,000$ in institutional savings over the study period.

Conclusions: A modified Fontan protocol resulted in reduced time to chest tube removal, hospital LOS, and chest tube drainage lasting $>1$ week. There was a strong trend toward avoiding nothing by mouth/total parenteral nutrition to control pleural effusion and lower hospital costs. (J Thorac Cardiovasc Surg 2015;150:481-7)

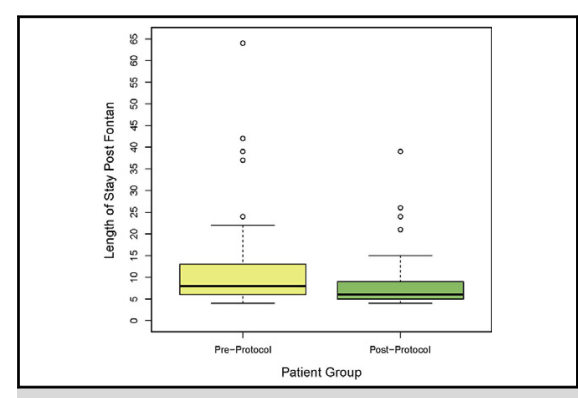

Comparison between groups in hospital length of stay measured in postoperative days.

\section{Central Message}

The use of a postoperative Fontan management protocol can reduce duration of chest tube drainage, hospital LOS, and hospital readmissions.

\section{Perspective}

Pleural effusions can complicate the postoperative course following the Fontan procedure The use of a modified Fontan management protocol mitigates prolonged pleural drainage and shortens hospital length of stay. It may also lead to a reduction in the incidence of readmission and lower costs.

See Editorial Commentary page 488.
During the past 40 years, the Fontan procedure has undergone many modifications to improve postoperative mortality and morbidity in children with univentricular hearts. Despite these advancements, pleural effusions continue to be a challenging problem in the immediate postoperative

\footnotetext{
From the a'Division of Cardiothoracic Surgery, Children's Hospital Los Angeles, Los Angeles, Calif; 'S School of Nursing, University of California Los Angeles, Los Angeles, Calif; and ${ }^{\mathrm{c}}$ Keck School of Medicine, University of Southern California, Los Angeles, Calif.

Received for publication Feb 10, 2015; revisions received June 9, 2015; accepted for publication June 14, 2015; available ahead of print Aug 5, 2015.

Address for reprints: Nancy A. Pike, PhD, RN, CPNP-AC, FAAN, School of Nursing, University of California Los Angeles, 700 Tiverton Ave, Factor Building Rm 3938, Los Angeles, CA 90025 (E-mail: npike@sonnet.ucla.edu). $0022-5223 / \$ 36.00$

Copyright (C) 2015 by The American Association for Thoracic Surgery http://dx.doi.org/10.1016/j.jtcvs.2015.06.042
}

period and a significant cause of morbidity and extended hospital length of stay (LOS). Currently, no definitive cause for pleural effusions has been identified. However, a number of potential factors include elevated pulmonary artery pressures (PAPs), ${ }^{1-4}$ reduced ventricular function, ${ }^{5,6}$ ventricle type, ${ }^{7}$ prolonged mechanical ventilation, moderate-to-severe systemic atrioventricular valve regurgitation, ${ }^{8}$ and longer cardiopulmonary bypass (CPB) and aortic crossclamp times. ${ }^{9-11}$ Other variables such as benefit of conduit type (lateral tunnel vs extracardiac), ${ }^{12}$ presence of fenestration, ${ }^{13-16}$ intraoperative techniques such as the use of modified ultrafiltration, ${ }^{17,18}$ off-pump techniques, $^{12,19}$ early extubation, ${ }^{20,21}$ and specific medication use or postoperative management regimens ${ }^{22-26}$ have been used in an attempt to reduce the incidence of pleural effusion and decrease hospital LOS. 


$$
\begin{aligned}
& \text { Abbreviations and Acronyms } \\
& \begin{aligned}
\text { CPB } & =\text { cardiopulmonary bypass } \\
\text { CTICU } & =\text { cardiothoracic intensive care unit } \\
\text { EC } & =\text { extracardiac } \\
\text { IQR } & =\text { interquartile range } \\
\text { LOS } & \text { length of stay } \\
\text { NP } & =\text { nurse practitioner } \\
\text { OR } & =\text { operating room } \\
\text { PAP } & =\text { pulmonary artery pressure } \\
\text { TPN } & =\text { total parenteral nutrition }
\end{aligned}
\end{aligned}
$$

Diuretic therapy, fluid restriction, and dietary modifications continue to be first-line treatment for persistent pleural effusions. Treatment may need to be escalated to further restrictions such as nothing by mouth with total parenteral nutrition (TPN) or, in extreme cases, pleurodesis or thoracic duct ligation. Some institutions have developed perioperative risk stratification strategies to guide patient selection and/or intra- and postoperative Fontan protocols to reduce the incidence of prolonged pleural effusions and the associated morbidities. ${ }^{22-25}$

Cava and colleagues ${ }^{22}$ published 1 of the first postoperative medical strategies to reduce the incidence of pleural effusions in Fontan patients. The medical strategy showed a significant decrease in chest tube duration from 15 to 6 days and hospital LOS from 18 to 9 days. ${ }^{22}$ However, hospital readmission rates for pleural effusion were not examined because the protocol ended with the removal of the last pleural chest tube. Recently, Sunstrom and colleagues ${ }^{26}$ showed improved outcomes and reduced LOS from 13 to 8 days using a Fontan intraoperative and postoperative management strategy named the PORTLAND (peripheral vasodilation, oxygen, restriction of fluids, technique of surgery, low-fat diet, anticoagulation [including antithrombin III management], no ventilator, and diuretics) protocol. The PORTLAND protocol shares many of the medical strategies used by Cava and colleagues. ${ }^{22}$

The purpose of our study was to describe the efficacy of our modified Fontan management protocol to reduce the duration of pleural drainage, hospital LOS, readmissions for pleural effusion, and health care costs.

\section{PATIENTS AND METHODS \\ Patient Selection}

Beginning in March 2006, we initiated our modified Fontan protocol. A retrospective review was performed of 125 consecutive patients who underwent a Fontan procedure who were discharged from the hospital during the 3-year period from January 2004 to February 2007. Patients were excluded if they died in the hospital $(\mathrm{n}=2)$ or underwent a Fontan conversion $(\mathrm{n}=3)$ for a total of 120 patients (60 preprotocol and 60 postprotocol) included in the analysis. A comparative design was used to assess group differences related to duration of pleural drainage, hospital LOS, readmission rates, and health care costs. Variables of interest included age, gender, weight, ethnicity, insurance type, ventricle type, diagnosis, preoperative hemodynamic parameters, presence of fenestration, concomitant procedures, extubation in the operating room (OR), median number of days until the last chest tube removed, amount of chest tube drainage 24 hours before removal, hospital LOS, need for nothing by mouth/TPN or pleurodesis, hospital readmissions for pleural effusion with and without chest tube reinsertion, and total hospital costs. The institutional review board at our institution approved this study as meeting ethical and legal requirements. Individual consent was waived.

\section{Institutional Practice/Operative Technique}

Since 2001, the practice at our institution has been to perform the modified Fontan procedure using an extracardiac (EC) conduit technique. Only 2 pediatric cardiothoracic surgeons were performing surgery during the study period. The EC Fontan procedure was performed consistently using CPB without aortic crossclamp unless a concomitant intracardiac procedure was performed. Modified ultrafiltration was rarely performed. After discontinuing $\mathrm{CPB}$, if the central venous pressure was $>18 \mathrm{~mm} \mathrm{Hg}$, with a transpulmonary gradient $>12 \mathrm{~mm} \mathrm{Hg}$, then placement of a fenestration was considered. If a fenestration was needed, a 4-mm direct side-to-side anastomosis of the EC conduit to the right atrial free wall was performed. The majority of patients were extubated in the OR. Patients were typically in the cardiothoracic intensive care unit (CTICU) for 3 days with the remainder of hospital stay in the telemetry unit. The postoperative anticoagulation regimen consisted of warfarin with a goal international normalized ratio of 1.5 to 2.0 for conduit prophylaxis.

\section{Cardiac Catheterization and Echocardiogram Data}

All patients underwent a preoperative Fontan cardiac catheterization and echocardiogram assessment. The mean PAP and transpulmonary gradient were documented. The degree of atrioventricular valve regurgitation and single ventricle function were obtained from the echocardiogram report.

\section{Modified Fontan Management Strategy Protocol}

The postoperative Fontan protocol was adapted from Cava and colleagues, ${ }^{22}$ published protocol at Children's Hospital Wisconsin (Table 1). The protocol was revised to coincide with our institutional practices and reviewed by the medical directors of the heart institute, CTICU, and pharmacy before implementation (Table 2). Once the protocol received internal approval, it was disseminated to private practice cardiology groups to solicit feedback and promote outpatient follow-up. The cardiothoracic surgery nurse practitioners (NPs) educated the nursing staff and other members of the health care team (ie, intensivists, fellows, and resident physicians), especially in the CTICU, where the protocol would be initiated. The NPs monitored adherence to the protocol in both the inpatient and outpatient settings.

\section{Outcome Measures}

The main outcome variables were duration of pleural drainage, hospital LOS, readmissions, and health care costs. Persistent pleural effusion was defined as chest tube drainage lasting $>1$ week. Hospital LOS included the day of admission to the day of discharge. All Fontan patients were admitted to the hospital the day of surgery. Hospital readmission for recurrent pleural effusion was a readmission within 30 days of hospital discharge. Hospital cost savings are defined as the money saved based on total costs as a result of protocol implementation.

\section{Statistical Methods}

Boxplots were created using R version 3.1.1 (R Foundation for Statistical Computing, Vienna, Austria) and all other analyses were conducted with the Statistical Package for the Social Sciences 2014 edition (IBMSPSS Inc, Armonk, NY). Preliminary analysis of patient characteristics among the pre- and postprotocol groups were summarized using descriptive statistics and differences were compared using the Mann Whitney $U$ 
TABLE 1. Wisconsin medical strategy to reduce chest tube drainage ${ }^{22}$

- Postoperative day 1 start intravenous furosemide $1 \mathrm{mg} / \mathrm{kg}$ every $8 \mathrm{~h} *$

- When taking liquids:*

Captopril maximum dose of $1 \mathrm{mg} / \mathrm{kg} /$ dose

Hydrochlorothiazide and spironolactone $1 \mathrm{mg} / \mathrm{kg}$ every $12 \mathrm{~h}$

- Fluid restriction of $80 \%$ maintenance

- Minimum of $0.5 \mathrm{~L}$ nasal cannula oxygen until all chest tubes are removed

- Low-fat diet (30\% of daily calories from fat)*

- Chest tubes removed when drainage decreased to $<2 \mathrm{~mL} / \mathrm{kg} / \mathrm{d}$

- End point of protocol is when chest tubes are removed

*Duration and conversion to home regimen not specified.

test for all continuous variables. Due to the highly skewed nature of the data, either $\chi^{2}$ or Fisher exact tests were used for all categorical variables, depending on whether or not the assumptions of the $\chi^{2}$ test could be met. One outlier in each group was eliminated secondary to postoperative complications related to noncardiac issues.

The total direct costs were calculated in each group using the financial information number for each patient's Fontan hospitalization encounter. Readmission encounters for pleural effusions were calculated separately. The mean total hospital cost savings for LOS and readmissions were calculated by subtracting the mean total costs in the preprotocol group from the mean total costs in the postprotocol group. This provided the unadjusted cost savings between groups. Total cost savings percentages were calculated for hospital LOS and readmissions by taking the average cost savings divided by the mean total cost in the preprotocol group.

\section{RESULTS}

\section{Patient Characteristics and Preoperative \\ Hemodynamic Parameters}

Demographic characteristics of groups showed no statistical difference in age, gender, weight, ethnicity, insurance, ventricle type, and single ventricle (Table 3). More than $50 \%$ of the sample in both groups was Hispanic with public insurance. There were also no statistical differences in preoperative hemodynamic and echocardiogram data

TABLE 2. Children's Hospital Los Angeles modified Fontan management protocol

- Postoperative day 1 start intravenous furosemide ( $1 \mathrm{mg} / \mathrm{kg} / \mathrm{dose})$ every 6-8 $\mathrm{h}$, convert to oral, 3 times a day, before discharge*

- When taking oral liquids start:*

Chlorothiazide ( $1 \mathrm{mg} / \mathrm{kg} /$ dose $)$ every $12 \mathrm{~h}$

Spironolactone $(1 \mathrm{mg} / \mathrm{kg} /$ dose $)$ every $12 \mathrm{~h}$

Enalapril starting dose $(0.05 \mathrm{mg} / \mathrm{kg} / \mathrm{dose})$ every $12 \mathrm{~h} \dagger$

- Warfarin $0.5 \mathrm{mg}$ orally every evening (goal international normalized ratio, 1.5-2.0)†

- Clear liquids and advance to a low-fat $\operatorname{diet}(30 \%$ daily calories from fat) for $6 \mathrm{wk}$

- Fluid restriction of $80 \%$ maintenance

- Minimum of $0.5 \mathrm{~L}$ nasal cannula oxygen until all chest tubes are removed

- Pleural chest tubes are not removed until the patient demonstrates the ability to take a low-fat diet and meet minimal chest tube output criteria $(<2 \mathrm{~mL} / \mathrm{kg}$ in $24 \mathrm{~h})$.

*All oral medications were continued in the outpatient setting for $2 \mathrm{wk}$ and weaned per the patient's cardiologist. †Titration based on patient tolerance and echo findings of systemic atrioventricular valve regurgitation. †़International normalized ratio of 1.5-2.0 is prophylaxis for conduit endothelialization.
TABLE 3. Fontan patient characteristics pre- and postprotocol

\begin{tabular}{lccc}
\hline \multicolumn{1}{c}{ Variables } & $\begin{array}{c}\text { Preprotocol } \\
(\mathbf{n}=\mathbf{6 0})\end{array}$ & $\begin{array}{c}\text { Postprotocol } \\
(\mathbf{n = 6 0 )}\end{array}$ & $\boldsymbol{P}$ value \\
\hline Age, y & $3(3-4)$ & $3(3-4)$ & .3 \\
Gender & & & .4 \\
$\quad$ Male & $30(50)$ & $35(58)$ & \\
Female & $30(50)$ & $25(42)$ & \\
Weight, kg & $14(12-16)$ & $14(12-15)$ & 1 \\
Ethnicity & & & .3 \\
Hispanic & $26(43)$ & $34(57)$ & \\
White & $18(30)$ & $12(20)$ & \\
Other & $16(27)$ & $14(23)$ & .7 \\
Insurance & & & \\
Public & $34(57)$ & $36(60)$ & \\
Private & $26(43)$ & $24(40)$ & \\
Ventricle type & & & \\
Left & $22(37)$ & $30(50)$ & .4 \\
Right & $30(50)$ & $22(37)$ & \\
Indeterminate & $8(13)$ & $8(13)$ & \\
Diagnosis* & & & \\
TA & $6(10)$ & $13(23)$ & \\
DILV & $10(17)$ & $5(9)$ & \\
DORV & $8(14)$ & $6(11)$ & \\
Unbalanced AVC & $9(15)$ & $9(16)$ & \\
HLHS & $19(32)$ & $17(30)$ & \\
PA/IVS & $6(10)$ & $4(7)$ & \\
Ebstein anomaly & $1(2)$ & $3(5)$ & \\
\hline
\end{tabular}

Values are presented as $\mathrm{n}(\%)$ or median (interquartile range). TA, Tricuspid atresia; $D I L V$, double inlet left ventricle; $D O R V$, double outlet right ventricle; $A V C$, atrioventricular canal defect, $H L H S$, hypoplastic left heart syndrome; $P A / I V S$, pulmonary atresia/intact ventricular septum. *One-sided Fisher exact test, the $P$ values are 2sided from $\chi^{2}$ tests, unless otherwise noted.

(Table 4). The difference in median PAP between groups was marginally significant at 11 days (interquartile range [IQR], 9-14 days) pre- versus 10 (IQR, 8-12 days) postprotocol $(P=.05)$, so analysis was performed using PAP as an ordinal value $\geq 15 \mathrm{~mm} \mathrm{Hg}$, which was not statistically significant $(P=.06)$.

\section{Chest Tube Drainage}

A comparison between groups of postoperative days before chest tubes were removed is depicted in Figure 1. The median number of days that the chest tubes were in place was 6 days (IQR, 5-10 days). This was significantly reduced in the postprotocol group to 4 days (IQR, 4-5 days) $(P<.0001)$. Twenty-three $(38 \%)$ preprotocol patients and $7(12 \%)$ postprotocol patients had persistent pleural effusions lasting $>1$ week $(P=.001)$. Furthermore, there was no need for nothing by mouth/TPN to treat persistent pleural effusions in the postprotocol group $0 \quad(0 \%)$ compared with the preprotocol $5(9 \%)$, which nearly reached statistical significance $(P=.06)$. The median pleural drainage 24 hours before chest tube removal was decreased in the postprotocol compared with the preprotocol group $(2 \mathrm{~mL} / \mathrm{kg} / \mathrm{d}$ [IQR, $1-4$ days] vs $3 \mathrm{~mL} / \mathrm{kg} / \mathrm{d}$ [IQR, $1-5$ days]; $P=.01$ ). During the Fontan admission, only 1 
TABLE 4. Preoperative and clinical variables related to pleural chest tube drainage pre- and postprotocol

\begin{tabular}{|c|c|c|c|}
\hline Variables & $\begin{array}{l}\text { Preprotocol } \\
\quad(\mathbf{n}=60)\end{array}$ & $\begin{array}{c}\text { Postprotocol } \\
(\mathbf{n}=60)\end{array}$ & $\begin{array}{c}P \\
\text { value }\end{array}$ \\
\hline \multicolumn{4}{|l|}{ Preoperative } \\
\hline PAP, $\mathrm{mm} \mathrm{Hg}$ & $11(9-14)$ & $10(8-12)$ & .05 \\
\hline $\mathrm{PAP} \geq 15 \mathrm{~mm} \mathrm{Hg} *$ & $12(20)$ & $4(6.7)$ & .06 \\
\hline TPG, $\mathrm{mm} \mathrm{Hg}$ & $5(3-6)$ & $5(4-6)$ & .1 \\
\hline$\geq$ Moderate systemic AVVR & $10(29)$ & $11(34)$ & .7 \\
\hline$>$ Mild ventricular dysfunction* & $7(12)$ & $2(3)$ & .2 \\
\hline \multicolumn{4}{|l|}{ Post-Fontan } \\
\hline Concomitant procedures & $10(17)$ & $9(15)$ & .8 \\
\hline Pulmonary arterioplasty & 6 & 3 & \\
\hline Tricuspid valvuloplasty & 3 & 2 & \\
\hline Pacemaker/maze & 1 & 4 & \\
\hline Fenestrated (Yes) & $12(20)$ & $12(20)$ & 1 \\
\hline Extubated in OR & $35(58)$ & $43(72)$ & .1 \\
\hline $\mathrm{NPO} / \mathrm{TPN}^{*}$ & $5(9)$ & $0(0)$ & .06 \\
\hline Last CT removed, $\mathrm{d}$ & $6(5-10)$ & $4(4-5)$ & $<.0001$ \\
\hline Pleural drainage $>1 \mathrm{wk}$ & $23(38 \%)$ & $7(12 \%)$ & .001 \\
\hline Median CT drainage & $3(1-5)$ & $2(1-4)$ & .01 \\
\hline $\begin{array}{l}\text { Last } 24 \mathrm{~h}(\mathrm{~mL} / \mathrm{kg} / \mathrm{d}) \mathrm{CT} \\
\text { reinsertion } \dagger\end{array}$ & $1(2)$ & $1(2)$ & 1 \\
\hline
\end{tabular}

Values are presented as median (interquartile range) or $\mathrm{n}(\%)$. Boldface indicates significant $P$ values $\geq .05$. PAP, Pulmonary artery pressure; $T P G$, transpulmonary gradient; $O R$, operating room; $A V V R$, atrioventricular valve regurgitation; $C T$, chest tube; $N P O / T P N$, nothing by mouth/total parenteral nutrition. *2-tailed Fisher exact test. $\dagger$ Related to pleural effusion, all tests are $\chi^{2}$ tests, unless otherwise noted.

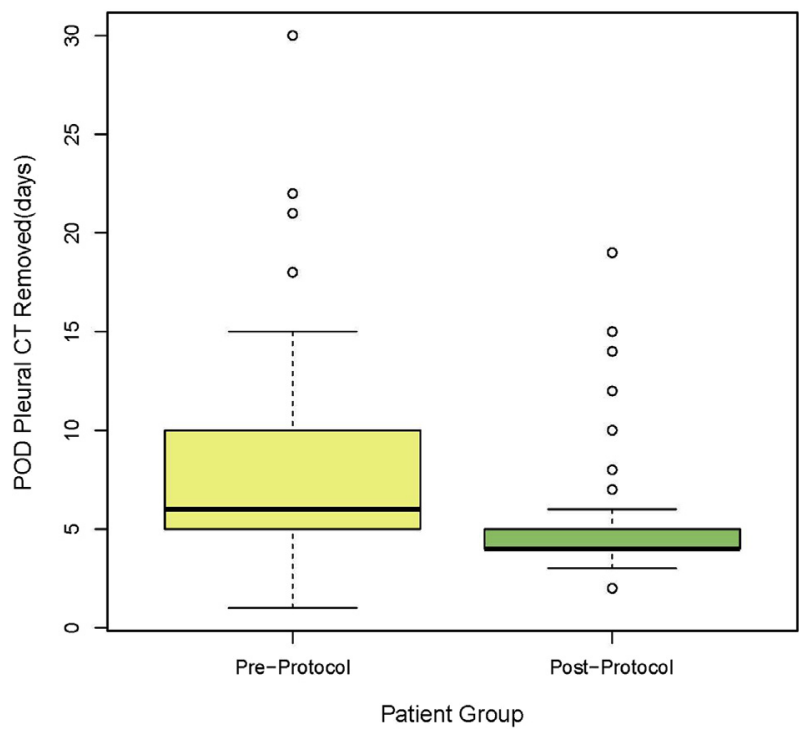

FIGURE 1. Duration of pleural drainage between groups as determined by the number of postoperative days (PODs) before chest tubes (CT) were removed. The bold horizontal black line indicates the median number of PODs before CTs were removed. Lighter horizontal lines framing the border of the box indicates the 25th and 75th percentiles for each patient group. The open circles indicate the outliers in each patient group and the whiskers depicted by the outer horizontal lines connected to the vertical dashed lines indicate the minimum and maximum values, excluding the outliers.

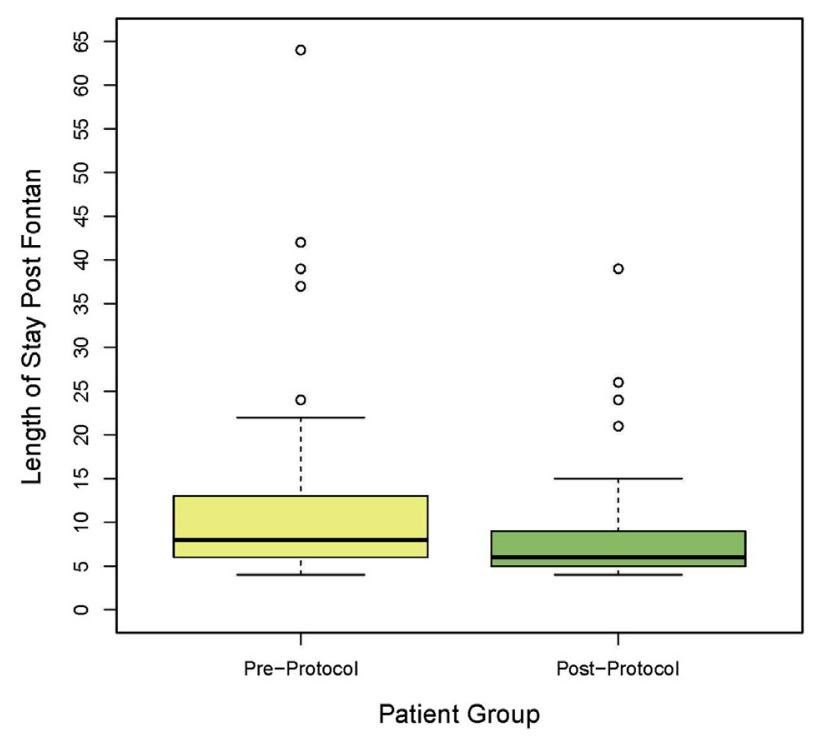

FIGURE 2. Comparison between groups in hospital length of stay measured in postoperative days. The bold horizontal black line indicates the median length of stay after Fontan. Lighter horizontal lines framing the border of the box indicates the 25th and 75th percentiles for each patient group. The open circles indicate the outliers in each patient group and the whiskers depicted by the outer horizontal lines connected to the vertical dashed lines indicate the minimum and maximum values, excluding the outliers.

pleural chest tube was reinserted in each group for accumulation of pleural fluid (Table 4).

\section{Hospital LOS, Readmissions, and Costs}

The median hospital LOS was reduced by 2 days in the postprotocol group compared with the preprotocol group (6 days [IQR, 5-9 days] vs 8 days [IQR, 6-13 days]; $P=.004)$ (Figure 2). Although hospital readmissions were reduced by $50 \%$ (14 vs $7 ; P=.09)$, this did not reach statistical significance (Table 5).

For the Fontan surgery hospitalization, the protocol reduced our institutional total costs by $\$ 9430(22 \%$; $P=.2$ ) per patient resulting in a direct cost savings of $\$ 385,457$. Fourteen patients were readmitted ( $<30$ days) in the preprotocol group compared with 7 in the postprotocol group. The average readmission hospital LOS was approximately 7 days in both groups. Average readmission cost savings were $\$ 5143(29 \% ; P=.5)$ per patient with a total direct cost saving $\$ 98,537$ comparing the pre- and postprotocol groups. The difference did not reach statistical significance. Our total institutional cost savings was $\$ 483,994$ for this time period.

\section{Discussion}

Our study findings demonstrate that with the initiation of a modified Fontan management protocol we had a significant decrease in postoperative days before chest tubes were 
TABLE 5. Fontan hospital length of stay (LOS), readmissions, and total hospital costs pre- and postprotocol

\begin{tabular}{lcccc}
\hline \multicolumn{1}{c}{ Variables } & Preprotocol $(\mathbf{n}=\mathbf{6 0})$ & Postprotocol $(\mathbf{n}=\mathbf{6 0})$ & $\boldsymbol{P}$ value & $\mathbf{9 5} \%$ Confidence interval \\
\hline Fontan hospital stay & & & $\mathbf{. 0 0 5}$ & $(-2123-14,433)$ \\
Hospital LOS & $8(6-13)$ & $6(5-9)$ & .1 & $(-4140-23,000)$ \\
Mean direct cost* & $28,471 \pm 29,024$ & $22,316 \pm 13,269$ & .2 & \\
Mean total cost* & $43,170 \pm 44,766$ & $33,740 \pm 27,212$ & & \\
Average cost savings & & $\$ 9430 /$ per patient & & \\
Average \% savings & & 22 & .1 & .5 \\
Readmission $<30$ d & $14(23)$ & $7(12)$ & .5 & $(-6740-13,099)$ \\
Readmission & $8(4-13)$ & $7(6-10)$ & $(-8690-21,422)$ \\
Hospital LOS & $10,897 \pm 3228$ & $7718 \pm 1503$ & \\
Mean direct cost* & $17,916 \pm 4832$ & $12,773 \pm 2331$ & \\
Mean total cost* & & $\$ 5143 /$ patient & \\
Average cost savings & & 29 & \\
Average $\%$ savings & & & \\
\hline
\end{tabular}

Values are presented as median (interquartile range), $\mathrm{n}(\%)$, or mean \pm standard deviation or standard error. LOS, Length of stay. *2-tailed independent $t$ test, all tests are $\chi^{2}$ tests, unless otherwise noted.

removed, pleural chest tube drainage $>1$ week, and hospital LOS. These findings are comparable to other Fontan management protocols ${ }^{22,26}$ except in a larger, homogeneous sample of EC Fontan patients, excluding the effects of other Fontan modifications and surgeon variations in the outcome. Furthermore, data were retrospectively reviewed over a relatively short 3 -year time period, providing less variability related to hospital perioperative and postoperative care practices.

The standardized protocol outlined by Cava and colleagues $^{22}$ was modified to comply with our institutional practices. Some of the protocol treatments were already being implemented preprotocol but in an inconsistent manner among providers in both the inpatient and outpatient settings. Aspects of the protocol that were modified due to lack of availability or pharmacy preferences were the use of chlorothiazide in place of hydrochlorothiazide and the use of enalapril instead of captopril. We used enalapril starting at a low dose of $0.05 \mathrm{mg} / \mathrm{kg}$ twice a day and individually optimized the dose based on echocardiography findings (eg, systemic atrioventricular valve regurgitation) and patient tolerance. The use of angiotensin-converting enzyme inhibitors remains controversial in reducing the duration of pleural drainage. ${ }^{9}$ Despite our previous retrospective study identifying angiotensin-converting enzyme inhibitors as a risk factor for persistent pleural effusion, we now believe further investigation is warranted. ${ }^{9}$ Additionally, the protocol required the use of supplemental nasal cannula oxygen (minimum $0.5 \mathrm{~L}$ ), regardless of systemic saturations, for the pulmonary vasodilatation effect until all chest tubes are removed. This treatment required diligent monitoring and staff reminders because the continued use of oxygen was not previously standard practice. Our preprotocol fluid and dietary restrictions were similar but adherence was not consistent. Postprotocol, all patients were placed on a fluid restriction of $80 \%$ maintenance and a low-fat diet for 6 weeks. To reduce the lymphatic strain during the initial postdischarge period, we changed the original protocol by extending the lowfat diet for a total of 6 weeks into the outpatient setting, regardless of the presence of a chylous effusion. Lastly, our pleural chest tube removal practice across both protocol groups was based on 24-hour drainage and a patient's ability to tolerate liquids and a low-fat diet. The protocol specified pleural tube removal based on 24-hour chest tube drainage $<2 \mathrm{~mL} / \mathrm{kg}$. In our study, the median pleural drainage before removal was $3 \mathrm{~mL} / \mathrm{kg} / \mathrm{d}$ preprotocol and $2 \mathrm{~mL} / \mathrm{kg} / \mathrm{d}$ postprotocol. Despite the approximately $1 \mathrm{~mL} / \mathrm{kg} / \mathrm{d}$ difference between groups, only 1 pleural chest tube was reinserted in each group secondary to accumulation of pleural fluid during the Fontan hospitalization. Therefore, the protocol recommendation of $<2 \mathrm{~mL} / \mathrm{kg} / \mathrm{d}$ might be liberalized to $<3 \mathrm{~mL} / \mathrm{kg} / \mathrm{d}$, which could potentially further reduce chest tube duration and hospital LOS.

A comparison of median hospital LOS between the preand postprotocol groups showed a statistically significant decrease from 8 to 6 days. The median hospital LOS postFontan procedure reported from single institutional experiences in the literature range from 8 to 23 days in patients both with and without Fontan fenestration. $1,4,16,17,19,24,26$ Furthermore, Jacobs and colleagues ${ }^{27}$ identified an average LOS of 13.4 days among 2691 Fontan patients in the Society of Thoracic Surgeons Congenital Heart Surgery Database. Our study reports the shortest median hospital LOS of 6 days post-Fontan.

A potential alternative explanation for our findings could be the decreased number of extubations in the OR and the higher proportion of single right ventricle patients in the preprotocol compared with the postprotocol group. Some studies identified right ventricle morphology as a risk factor for chest tube duration and ultimately increased hospital LOS. $^{7,17}$ Other studies demonstrated decreased chest tube output and hospital LOS with early extubation in the $\mathrm{OR}^{20,21}$ by mitigating the negative effects of positive 
pressure ventilation. Despite these differences, our study showed no statistical difference between groups by ventricle type $(P=.292)$ or by undergoing extubation in the OR $(P=.126)$. The use of inpatient NPs could further explain our findings of decreased hospital LOS and patient readmissions for pleural effusion through vigilant patient monitoring and early identification and treatment. However, the NPs provided the same inpatient and outpatient follow-up across the 3-year period reviewed for this study.

The pleural chest tube drainage and duration influences hospital LOS. In our study, median pleural chest tube duration was reduced from 6 days preprotocol to 4 days postprotocol. Patients were typically discharged within 24 hours of removal of the last chest tube unless further education or medication adjustments were needed. Other Fontan protocols also demonstrated a reduction in pleural drainage from 15 to 6 days $^{22}$ and 11 to 6 days, ${ }^{26}$ with an average duration of chest tube drainage of 5 to 18 days both with and without Fontan fenestration reported in single-center studies. $^{4,10,11,16,17,19,24,26,27}$

Our institution has now further modified the Fontan protocol to discontinue the fluid restriction of $80 \%$ maintenance 24 to 48 hours before discharge. This allows a more realistic posthospital patient intake pattern while monitoring by chest radiograph for accumulation of pleural fluid and making any final adjustments to the diuretic regimen before discharge. This liberalization of fluid intake before discharge could potentially further reduce hospital readmissions for accumulation of pleural fluid. Patients are typically followed by the surgical team in the outpatient setting for 2 clinic visits, during which diuretics can be adjusted based on chest radiograph findings.

In our study, hospital readmission rates were reduced by $50 \%$ postprotocol. Hospitals are now being penalized for excessive readmissions under the Patient Protection and Affordable Care Act. $^{28}$ As a result, intense efforts to decrease hospital 30-day readmission rates are a priority at most adult hospitals. To date, children's hospitals have not been targeted, but often policies that start in adult facilities eventually migrate to pediatrics. In general, readmission rates are lower in children than adults with the highest rates being in children with chronic medical conditions and with public insurance. ${ }^{28,29}$ In our study, $58 \%$ of Fontan patients received public or state-funded health insurance. Hispanic ethnicity comprised almost $50 \%$ of the Fontan population in both protocol groups, which reflects the high-risk, ethnically diverse population in the City of Los Angeles compared with other large multicenter Fontan studies in which the ethnicity is predominantly white $(80 \%) .{ }^{30}$ Furthermore, all 7 readmissions in the postprotocol group were for symptomatic pleural effusion. Only 1 parent was reported as being noncompliant with a child's medication administration that resulted in a recurrent pleural effusion. Gorden and colleagues ${ }^{24}$ reported readmission rates as high as $37 \%$ within 30 days post-Fontan procedure with $68 \%$ of those readmissions due to recurrent pleural effusion. Sunstrom and colleagues $^{26}$ reported a decrease in hospital readmissions to $14 \%$ with the use of a Fontan management protocol. By reducing hospital readmission rates for pleural effusions after the Fontan procedure, we can avoid potential future penalties in the statefunded insurance system.

Although not statistically significant, the use of the Fontan protocol showed a total cost savings of $22 \%$ and $29 \%$ with hospital LOS and readmission, respectively. Only 1 study has assessed cost saving post-Fontan with the use of a clinical pathway to facilitate early hospital discharge. ${ }^{11}$ A cost savings of $\$ 38,000$ per patient was reported due to a reduced hospital LOS from an estimated 15 days on a traditional pathway to 4 days. ${ }^{24}$ However, the significant reduction in hospital days and increased cost savings reflects the use of pleural Blake drains in the outpatient setting to facilitate earlier discharge. Our study demonstrated a 6day median hospital LOS with $\$ 9430$ cost savings per patient. Relatively, this figure may seem insignificant, but in the 60 patients in our postprotocol group this amounted to a $\$ 385,457$ direct cost savings in hospital LOS and $\$ 98,537$ in readmissions for a total direct cost savings of $\$ 483,994$ to our institution.

\section{Limitations}

Our findings should be interpreted in light of some limitations. This was a single-center study that performs only the EC Fontan procedure, which limits the generalizability to all Fontan types. There were more single left ventricle Fontan patients and extubations in the OR in the postprotocol group, which could explain our improvement in all outcome variables. Although we believe the protocol was beneficial, there might be other unquantifiable changes such as improved postoperative medical management or more focused team management over the 3-year review. We also believe the protocol had strong adherence by our institution with only a rare transient deviation related to hypotension or electrolyte disturbances. However, we did not collect data on protocol adherence nor analyze the effectiveness of each protocol intervention due to the retrospective study design. The preoperative echocardiogram variables of ventricular function and atrioventricular valve regurgitation were subjectively evaluated by different cardiologists, which could produce variable interpretations. In addition, our cost data reflect an earlier surgical era, which makes it difficult to compare with current health care costs. Lastly, the causal association of hospital LOS and readmissions could not be adequately established because of the retrospective design of the study. 


\section{CONCLUSIONS}

Pleural effusions after the Fontan procedure continue to be a challenging problem. The use of a modified Fontan management protocol has improved outcomes up to 30 days postoperation and can effectively decrease the duration of pleural chest tube drainage, hospital LOS, readmissions, and ultimately health care costs.

\section{Conflict of Interest Statement}

Authors have nothing to disclose with regard to commercial support.

\section{References}

1. Mascio CE, Wayment M, Colaizy TT, Mahoney LT, Burkhart HM. The modified Fontan procedure and prolonged pleural effusions. Am Surg. 2009;75:175-7.

2. Yun TJ, Im YM, Jung SH, Jhang WK, Park JJ, Seo DM, et al. Pulmonary vascular compliance and pleural effusion duration after the Fontan procedure. Int J Cardiol. 2009;133:55-61.

3. Rogers LS, Glatz AC, Ravishankar C, Spray TL, Nicolson SC, Rychik J, et al. Eighteen years of the Fontan operation at a single center. J Am Coll Cardiol. 2012;60:1018-25.

4. Fedderly RT, Whitstone BN, Frisbee SJ, Tweddell JS, Litwin SB. Factors related to pleural effusions after Fontan procedure in the era of fenestration. Circulation. 2001;104(Suppl I):I-148-51.

5. Border WL, Syed AU, Michelfelder EC, Khoury P, Uzark KC, Manning PB, et al. Impaired systemic ventricular relaxation affects postoperative short-term outcomes in Fontan patients. J Thorac Cardiovasc Surg. 2003;126:1760-4.

6. Garofalo CA, Cabreriza SE, Quinn A, Weinberg AD, Printz BF, Hsu DT, et al. Ventricular diastolic stiffness predicts perioperative morbidity and duration of pleural effusions after the Fontan operation. Circulation. 2006;114(Suppl I): I-56-61.

7. Julsrud PR, Weigel TJ, Van Son JA, Edwards WD, Mair DD, Driscoll DJ, et al. Influence of ventricular morphology on outcome after the Fontan procedure. Am J Cardiol. 2000;86:319-23.

8. Mascio CE, Austin EH. Pleural effusions following the Fontan procedure. Curr Opin Pulm Med. 2010;16:362-6.

9. Gupta A, Daggett C, Behera S, Ferraro M, Wells W, Starnes V. Risk factors for persistent pleural effusions after the extracardiac Fontan procedure. J Thorac Cardiovasc Surg. 2004;127:1664-9.

10. Salvin JW, Scheurer MA, Laussen PC, Mayer JE, del Nido PJ, Pigula FA, et al. Factors associated with prolonged recovery after the Fontan operation. Circulation. 2008;118(Suppl 1):S171-6.

11. Tweddell JS, Nersesian M, Mussatto KA, Nugent M, Simpson P, Mitchell ME, et al. Fontan palliation in the modern era: factors impacting mortality and morbidity. Ann Thorac Surg. 2009;88:1291-9.

12. Ovroutski S, Sohn C, Miera O, Peters B, Alexi-Meskishvili V, Hetzer R, et al. Improved early postoperative outcomes for extracardiac Fontan operation without cardiopulmonary bypass: a single-centre experience. Eur J Cardiothorac Surg. 2013;43:952-7.

13. Lemler MS, Scott WA, Leonard SR, Stromberg D, Ramaciotti C. Fenestration improves clinical outcomes of the Fontan procedure: a prospective, randomized study. Circulation. 2002;105:207-12.
14. Fiore AC, Tan C, Armbrecht E, Huddleston CB, Kim E, Goel N, et al. Comparison of fenestrated and nonfenestrated patients undergoing extracardiac Fontan. Ann Thorac Surg. 2014;97:924-31.

15. McGuirk SP, Winlaw DS, Langley SM, Stumper OF, de Giovanni JV, Wright JG, et al. The impact of ventricular morphology on midterm outcome following completion total cavopulmonary connection. Eur J Cardiothorac Surg. 2003; 24:37-46.

16. Atz AM, Travison TG, McCrindle BW, Mahony L, Quartermain M, Williams RV, et al. Late status of Fontan patients with persistent surgical fenestration. J Am Coll Cardiol. 2011;57:2437-43.

17. Gaynor JW, Bridges ND, Cohen MI, Mahle WT, Decampli WM, Steven JM, et al Predictors of outcomes after the Fontan operation: is hypoplastic left heart syndrome still a risk factor? J Thorac Cardiovasc Surg. 2002;123:237-45.

18. Koutlas TC, Gaynor JW, Nicolson SC, Steven JM, Wernovsky G, Spray TL. Modified ultrafiltration reduces postoperative morbidity after cavopulmonary connection. Ann Thorac Surg. 1997;64:37-43.

19. Shikata F, Yagihara T, Kagisaki K, Hagino I, Shiraishi S, Kobayashi J, et al. Does the off-pump Fontan procedure ameliorate the volume and duration of pleural and peritoneal effusions? Eur J Cardiothorac Surg. 2008;34:570-5.

20. Morales DL, Carberry KE, Heinle JS, McKenzie ED, Fraser CD, Diaz LK. Extubation in the operating room after the Fontan's procedure: effect on practice and outcomes. Ann Thorac Surg. 2008;86:576-82.

21. Mutsuga M, Quinonez LG, Mackie AS, Norris CM, Marchak BE, Rutledge JM et al. Fast-track extubation after modified Fontan procedure. J Thorac Cardiovasc Surg. 2012;144:547-52.

22. Cava JR, Bevandic SM, Steltzer MM, Tweddell JS. A medical strategy to reduce persistent chest tube drainage after the Fontan operation. Am J Cardiol. 2005;96: 130-3.

23. Jacobs ML, Pelletier GJ, Pourmoghadam KK, Mesia CI, Madan N, Stern H, et al Protocols associated with no mortality in 100 consecutive Fontan procedures. Eur J Cardiothorac Surg. 2008;33:626-32.

24. Gorden BM, Hasaniya NW, Newcombe JB, Daher NS, Jodhka U, Razzouk AJ, et al. Blake drains: a novel method of chest drainage after extracardiac Fontan operation with autologous pericardium. Ann Thorac Surg. 2012;94:1289-94.

25. Fancois K, Bove T, De Groote K, Panzer J, Vandekerckhove K, Suys B, et al. Pleural effusions, water balance mediators and the influence of lisinopril after completion Fontan procedures. Eur J Cardiothorac Surg. 2009;36:57-62.

26. Sunstrom RE, Muralidaran A, Gerrah R, Reed RD, Good MK, Armsby LR, et al A defined management strategy improves early outcomes after the Fontan procedure: the Portland protocol. Ann Thorac Surg. 2015;99:148-55.

27. Jacobs JP, O'Brien SM, Pasquali SK, Jacobs ML, Lacour-Gayet FG Tchervenkov CI, et al. Variation in outcome for benchmark operations: an analysis of the Society of Thoracic Surgeons Congenital Heart Surgery Database. Ann Thorac Surg. 2011;92:2184-91.

28. Berry JG, Toomey SL, Zaslavsky AM, Jha AK, Nakamura MM, Klein DJ, et al. Pediatric readmission prevalence and variability across hospitals. JAMA. 2013; 309:372-80.

29. Gay JC, Hain PD, Grantham JA, Saville BR. Epidemiology of 15 day readmissions to a children's hospital. Pediatrics. 2011;127:e1505-12.

30. Anderson PA, Sleeper LA, Mahony L, Colan SD, Atz AM, Breitbart RE, et al. Pediatric Heart Network Investigators. Contemporary outcomes after the Fontan procedure: a Pediatric Heart Network multicenter study. J Am Coll Cardiol. 2008; 52:85-98.

Key Words: Fontan, congenital heart disease, pleural effusion, protocol, postoperative care 